\title{
A CFD Simulation on How the Different Sizes of Silica Gel Will Affect the Adsorption Performance of Silica Gel
}

\author{
John White \\ School of Engineering, University of Birmingham, Birmingham B15 2TT, UK \\ Correspondence should be addressed to John White, jxw998@bham.ac.uk \\ Received 6 December 2011; Revised 12 January 2012; Accepted 17 January 2012 \\ Academic Editor: Guan Heng Yeoh \\ Copyright () 2012 John White. This is an open access article distributed under the Creative Commons Attribution License, which \\ permits unrestricted use, distribution, and reproduction in any medium, provided the original work is properly cited. \\ The application of computational fluid dynamics (CFD) in the area of porous media and adsorption cooling system is becoming \\ more practical due to the significant improvement in computer power. The results from previous studies have shown that CFD \\ can be useful tool for predicting the water vapour flow pattern, temperature, heat transfer, flow velocity, and adsorption rate. This \\ paper investigates the effect of silica gel granular size on the water adsorption rate using computational fluid dynamics.
}

\section{Introduction}

The adsorption properties of silica gel have been studied for many years as silica gel is used in many industries including adsorption cooling systems. Past research have shown experimentally that the adsorpitivity of silica gel granules depend on their size. The purpose of this work was to study the effect of granule size on the adsorption properties of silica gel by using CFD and comparing the simulation results to those obtained experimentally.

To design an efficient adsorber bed, flow, and temperature, adsorption information is essential. Studies of fluid dynamics and heat transfer in adsorber beds date back to the early twentieth century [1] (Andersson, 1961.) The early investigation of flow in porous media packed beds provided mainly such bulk information as pressure drop correlations [2]. Predict pressure loss for flow in adsorber beds [3, 4]. Computational fluid dynamics (CFD) provides an innovative approach to model and analysing the local flow and the effect of silica gel size on adsorption performance of a packed bed. CFD simulation of porous media local flow and heat transfer based on CFD technique has increasingly been reported in recent years in fields of packed bed flow and heat transfer modelling $[5,6]$. CFD simulation was based on fundamental principles of diffusion and adsorption/desorption of porous materials. In this study, an integrated CFD model was developed to model and simulate the adsorption dynamics of water vapour in three different sizes of silica gel in a fixed bed adsorption column. The developed integrated model was used to determine the adsorption capacity of the three silica gel as a function of time, based on different operating conditions.

The simulated results were compared with pass research papers experimental data and found to give a good agreement. The effect of various influencing parameters such as velocity and silica gel porosity were studied to investigate their influences on the adsorption capacity.

\subsection{Methods}

1.1.1. 3D Geometry of Silica Gel Packing. Geometric models of the silica gel adsorber bed systems are generated for a tube of $25 \mathrm{~mm}$ length of $100 \mathrm{~mm}$ diameter.

The size of silica gel that are use in this CFD simulation is

Silica gel granular size $1 \mathrm{~mm}$

Silica gel granular size $2 \mathrm{~mm}$

Silica gel granular size $3 \mathrm{~mm}$.

Adsorbent particle size affects how the water vapour flows through the adsorber bed. Smaller particles (higher mesh values) larger particles (lower mesh values).

First we selected the silica gel to particle sizes the silica gel were selected in the ranges of 40-60 mesh, 60-100 mesh, and 100-200 mesh. 


\section{Modelling Strategies for Silica Gel Adsorber Beds}

In this study, an integrated CFD model was developed to simulate the adsorption dynamics of water vapour of silica gel granules in a fixed bed adsorption column using the solidworks flow simulation module. The model consists of two modes of operation, the water vapour adsorption and the desorption mode. In each mode, the water vapour flow profile surrounding the granules was determined by solving the Navier-Stokes equations and the resulting velocity profile was regarded time invariant and stored for later use. Also, the time-dependent mass transfer both outside and inside the porous silica gel due to its adsorpitivity was simulated through a user-defined function developed to solve the Brunauer, Emmett and Teller (BET) equation [1] for both adsorption and desorption processes. The developed model was used to determine the adsorption capacity of three different sizes of silica gel granules namely; $1 \mathrm{~mm}, 2 \mathrm{~mm}$, and $3 \mathrm{~mm}$ as a function of time at different operating temperatures. The simulation results were compared with past experimental data and found to give a good agreement.

2.1. Modelling of Vapour Flow in Silica Gel Particle. The porous media capabilities of flow simulation are used to simulate a porous media silica gel which allows you to model the volume that the silica gel occupies as a distributed resistance instead of discretely modelling all of the individual passages within the silica gel, which would be impractical or even impossible. We consider the influence of the porous medium permeability type (isotropic and unidirectional media of the same resistance to flow) on the water vapour mass flow rate distribution over the silica gel. We will observe the latter through the behaviour of the water vapour flow trajectories distributed uniformly over the model's inlet and passing through the porous silica gel. Additionally, by cooling the flow trajectories by the flow velocity the vapour residence time in the porous media can be estimated, which is also important from the silica gel adsorption of water vapour effectiveness viewpoint. As a first introduction to CFD a simple model was created the model represented one silica granule in a tube as shown in (Figure 1) the flow inlet and flow outlet.

The silica gel granule in the tube was designed with the dimensions of $1 \mathrm{~mm}, 2 \mathrm{~mm}$ and $3 \mathrm{~mm}$ this was then used in the validation model. With this model it was tried to fit CFD data to generally accepted experimental data. This one granule was then clone to 40 granule 60 and 120 these clone granule was then simulated in a tube bed (see Figure 2).

This limitation of granules was necessary to keep the model reasonable in size with a mesh density comparable to the validation model. A series of runs was conducted at a number of flow velocities, see Table 3 . In all these runs, the centrally located granules had a defined temperature of $20^{\circ} \mathrm{C}$. The tube wall temperature was set at $20.5^{\circ} \mathrm{C}$ to create a $0.5^{\circ} \mathrm{C}$ temperature difference between the granule and the fluid at infinite distance. The water vapour that flowed through the tube was defined at $20^{\circ} \mathrm{C}$ at the entrance. The temperature of the through the granules was simulated and recorded.

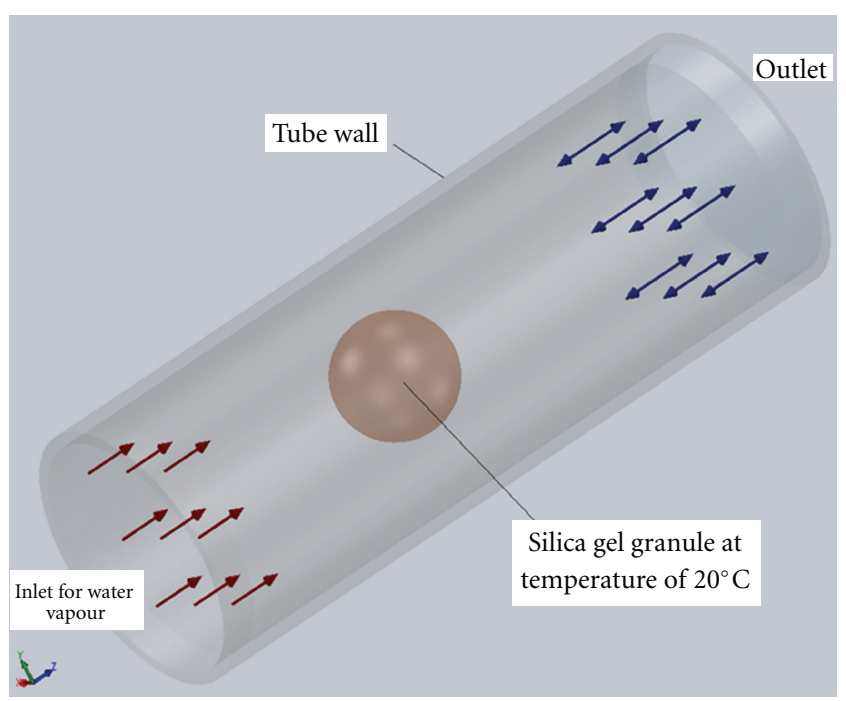

FIGURE 1: One silica gel in a tube geometry used for validation of CFD against theoretical models.

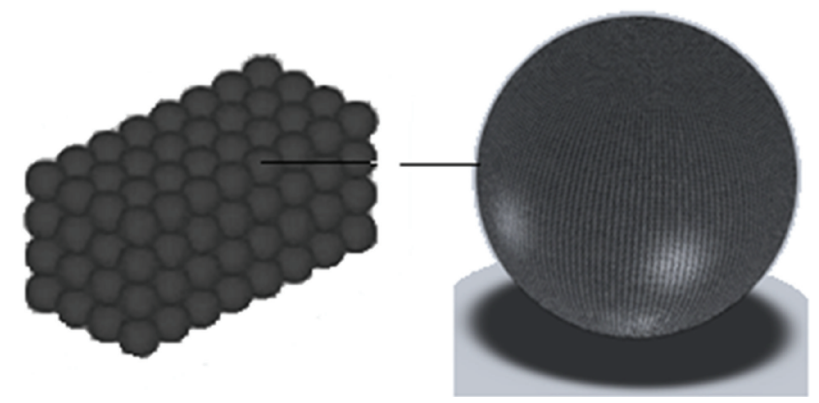

FIGURE 2: This one granule was then clone to 36 granule 65 and 114 granules.

A constant diffusion coefficient $D_{e}$ was assumed according to the reference of [7] Sakoda et al. (1984). The spherical silica gel particle with initial conditions of water content $m_{r}=0$ and a temperature $T_{\text {in }}$ is instantaneously exposed to vapour flow. The diffusion equation in the silica gel particle is

$$
\frac{\partial m_{r}}{\partial t}=\frac{1}{r^{2}} \frac{\partial}{\partial r}\left(D_{e} r^{2} \frac{\partial m_{r}}{\partial_{r}}\right) .
$$

The initial condition and boundary conditions for (1) are

$$
\begin{gathered}
m_{r}(r ; t=0)=0 \\
\left.\frac{\partial m_{r}}{\partial r}\right|_{r=0}=0 \\
m_{r}\left(r=\frac{d_{p}}{2}, t\right)=m_{s}(T, x, P) .
\end{gathered}
$$

The $m_{r}$ is local water content of a silica gel particle in the radial direction and the $m_{e}$ is the equilibrium water content on the particle surface. The water content averaged in a silica gel particle is given by

$$
m=\frac{24}{d_{p}^{3}} \int_{0}^{d p / 2}\left(1-e_{p}\right) r^{2} m_{r} d r
$$


where the porosity in a silica gel particle was fixed at $e_{p}=$ 0.38 for $1 \mathrm{~mm}$ silica gel, 0.38 for $2 \mathrm{~mm}$ silica gel and 0.34 for the $3 \mathrm{~mm}$ silica gel.

\section{CFD Governing Equations}

The transport phenomena can be divided into adsorption and water vapour flow in the adsorber bed, silica gel granules surfaces Navier-Stokes equations for flow are used to solve the water vapour flow phase $[1,3,7-11]$ :

$$
\begin{gathered}
\frac{\partial \vec{u}}{d t}=-\frac{1}{\rho} \nabla p+\eta \Delta \vec{u}, \\
\nabla \cdot \vec{u}=0 .
\end{gathered}
$$

The $p$ represents pressure, $\eta$ dynamic viscosity and $\rho$ density of the fluid the velocity flow can be simulated in first. This simulated data is then stored and used for solving the convection-diffusion equation [1]:

$$
\frac{\partial c}{\partial t}=-\vec{u} \cdot \nabla c+D \cdot \Delta c .
$$

The $c$ represents the water vapour molecule adsorbed into the silica gel, and $D$ the diffusion flow coefficient in the silica gel. In contrast to diffusion, an effective diffusivity $D_{e}$ must be applied [1,3,9-11]:

$$
\begin{gathered}
\frac{\partial c_{p}}{\partial t}=D_{e} \cdot \Delta c_{p}-\frac{1-\varepsilon_{e}}{\varepsilon_{e}} \frac{\partial q}{\partial t} \\
D_{e}=\frac{\varepsilon_{i} D}{\theta}
\end{gathered}
$$

The $c_{p}$ represents the water vapour molecule adsorbed within the silica gel particle. The mass transfer resistance between the silica gel surface is also modelled [1]:

$$
\begin{gathered}
\vec{n} \cdot(-D \nabla c+c \vec{u})=k_{f}\left(c-c_{p}\right), \\
-\vec{n} \cdot\left(-D_{e} \nabla c_{p}+c_{p} \vec{u}\right)=k_{f}\left(c_{p}-c\right) .
\end{gathered}
$$

The $\vec{n}$ represents the normal vector of the outer silica surface. The driving force of transport over the particle boundary is relative to the adsorption difference, and $k_{f}$ is the corresponding mass transfer coefficient. The adsorber beds in the CFD simulation are simulated with far less silica gel granules than in a real adsorber bed. In order to simulate similar systems, the effective diffusivity $D_{e}$ is increased. The adsorption of the water vapour molecules at the silica surfaces is described by a classical Langmuir-type kinetic $[1,3,7-10]$ :

$$
\frac{\partial q}{\partial t}=k_{a} \cdot c \cdot\left(q_{\max }-q\right)-k_{d} \cdot q .
$$

The $k_{a}$ and $k_{d}$ represent adsorption and desorption rates, $q_{\max }$ maximum capacity, and $q$ the current occupation of binding sites at the surface.
3.1. Desorption of Vapour in Porous Materials. When considering desorption in a porous material one must considers vapour transport the Lattice Boltzmann equation can be expressed as

$$
\frac{\partial s}{\partial t}=r\left(k_{p} c^{p}-s^{q}\right) .
$$

This can be done with Lattice Boltzmann multi physics extension by applying a local rule describing the change of the adsorption rate $\partial s / \partial t$ on the water vapour concentration $C$ and the adsorbed mass $S$ deposited per unit volume of the porous media matrix.

With parameters $k_{p}>0$ and exponents $p, q$ fulfilling $p / q \leq 1$. At equilibrium, that is, for $\partial s / \partial t=0$, this model reduces to a Freundlich isotherm:

$$
s=k c^{n},
$$

with $k=k_{p}^{1 / q}$ and $n=p / q$.

\section{CFD Modelling Method}

In all types of CFD modelling there are some factors that determine the difficulty of modelling granules packed adsorption beds. In a silica gel packed bed the amount of packing and the narrow region between them makes its modelling more complicated. One way of solving this problem is to model a single granule of silica gel in CAD software.

This single granule can then be clone into thousands of granule then pack into a 3D adsorption bed (see Figure 3). The clone pack silica gel can then be inserted as a parasolid CAD file then one could applied a porous media material using a CFD software called flow simulation. Then, this porous media could be solved by using a finite controlvolume method.

4.1. Smaller Arrangements of Silica Gel Granules. The amount of silica gel granules in a real adsorber bed cannot be reproduced in a three-dimensional model using CFD tools. However, to simplify the numerical calculations you can simulate smaller arrangements of silica gel granules. In this study, there are three silica gel sizes in the adsorber beds these beds contain 36,65 , and 114 particles, respectively (see Figure 4).

Different porosities were obtained by changing the particle sizes and arrangements. Constant thermo physical properties at $20^{\circ} \mathrm{C}$ were assumed for the water vapour. Periodic boundary conditions were imposed on the boundaries of the computational domain. The inflow into the domain was set as a velocity inlet with the outflow set as the pressure outlet boundary condition. The dimensions and porosities of the porous media used in the simulation were based on the experimental research are listed in Table 1 . The constant contact areas between the particles were calculated based on the desired porosity.

4.2. Computational Mesh Domain. In this work, the mesh creation was done using flow simulation, a general-purpose 


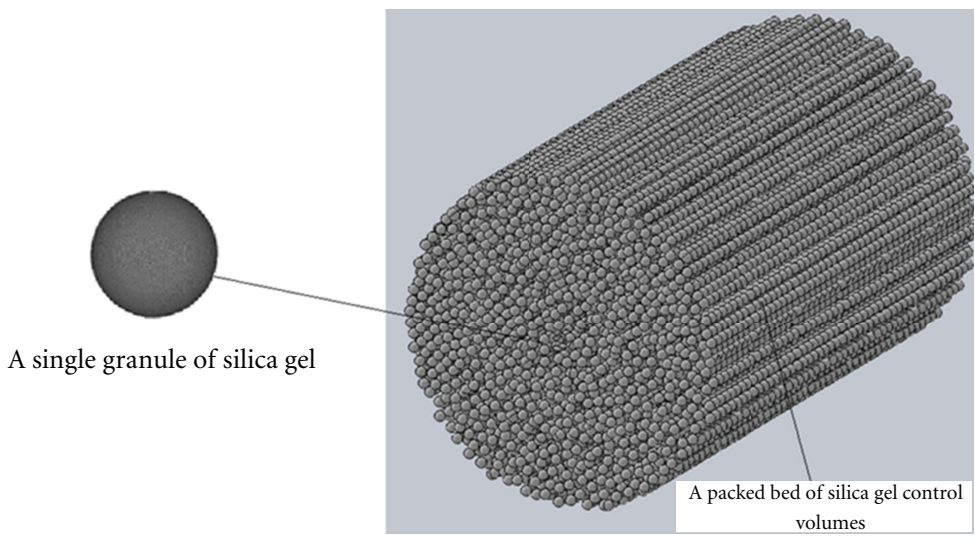

FIGURE 3: Thousands of granule pack the silica gel into a 3D adsorption bed.

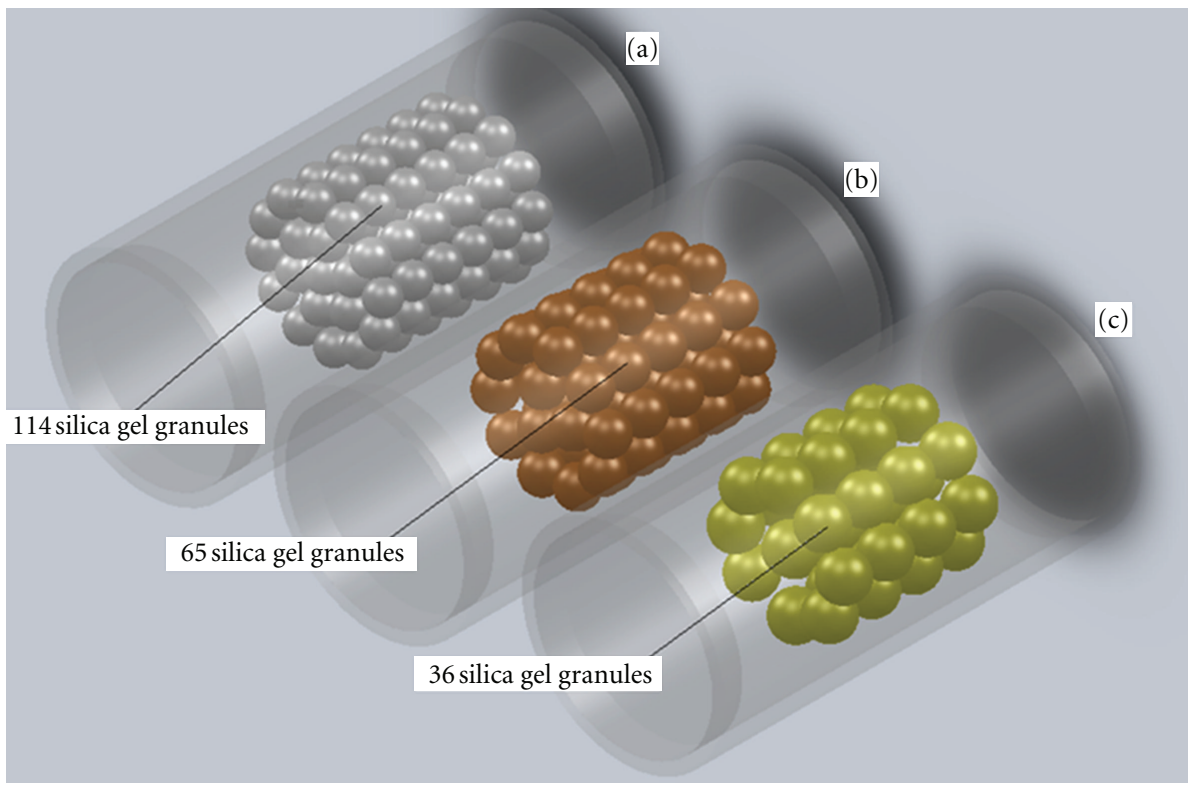

FIGURE 4: The three adsorption bed tube containing the numerically created example packing with (a) 36 granules, (b) 65 granules, (c) 114 granules.

TABLE 1: Geometry and mesh parameters.

\begin{tabular}{lccc}
\hline Test section & $\begin{array}{c}\text { Porous media sizes } \\
(\mathrm{mm})\end{array}$ & Porosity $\varepsilon$ & $\begin{array}{c}\text { Total number of } \\
\text { elements }\end{array}$ \\
\hline No. 1 & $1 \mathrm{~mm}$ & 0.38 & 1065623 \\
No. 2 & $2 \mathrm{~mm}$ & 0.38 & 1122425 \\
No. 3 & $3 \mathrm{~mm}$ & 0.34 & 1097191 \\
\hline
\end{tabular}

program providing a variety of automatic meshing strategies. All the simulation, in this exercise were conducted first with automatic meshing and then secondly modified manually to help determine the influence of mesh density on the outcome of the simulation.

4.3. A Porous Sample with Nonuniform Porosity. The mesh domain was split into 1065623 cells containing 1122425 faces and 1097191 nodes.
The grid was then partitioned along the principal axis into 3 segments to allow the domain to reduce simulation time on computer see Figure 5.

4.4. 3D Silica Gel Granules Packing Arrangements. When simulating the adsorption of water vapour on porous silica gel the volume of silica gel packing and pore spacing will depend upon the size of silica gel. But in some sense the relationship between size and pore spacing can be more complex because of the influence of packing arrangements.

For example, the packing of spherical porous media of $1 \mathrm{~mm}$ uniform size in Figure 6(a) when a simulation was completed on this type of packing arrangement, the porosity was 0.45 . But when the simulation was simulated in Figure $6(\mathrm{~b})$ the porosity was 0.26 and when a simulation was completed in the Figure 6(c), it was 0.38 , this arrangement was a more realistic packing arrangement, this was a random arrangement. In a real-world scenario, adsorption bed would 


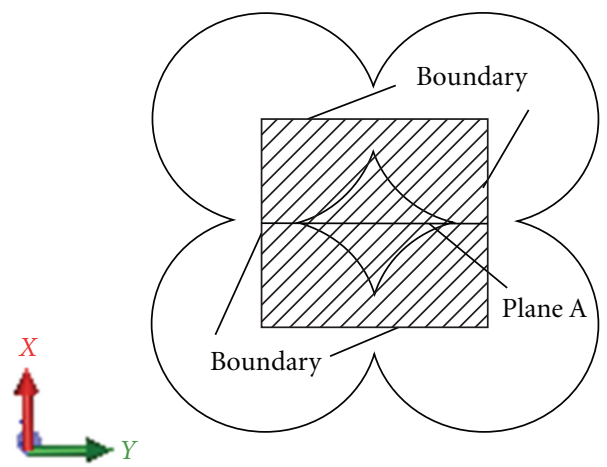

(a)

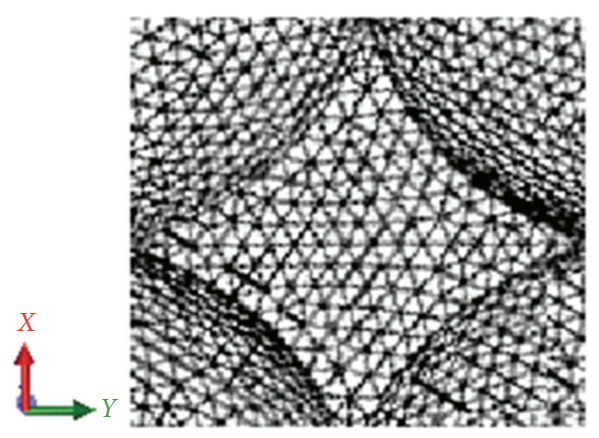

(b)

FIGURE 5: Schematic diagram of the computational domain.

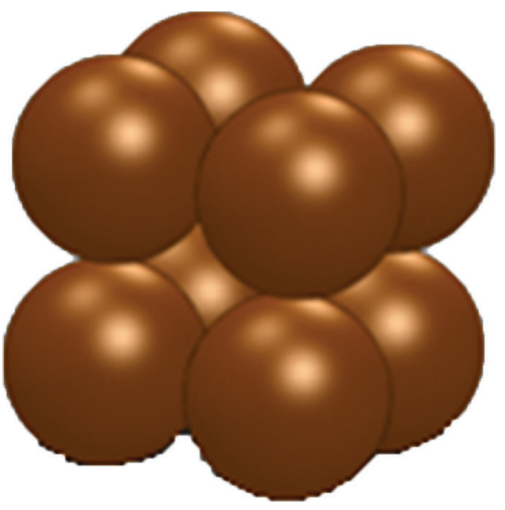

(a)

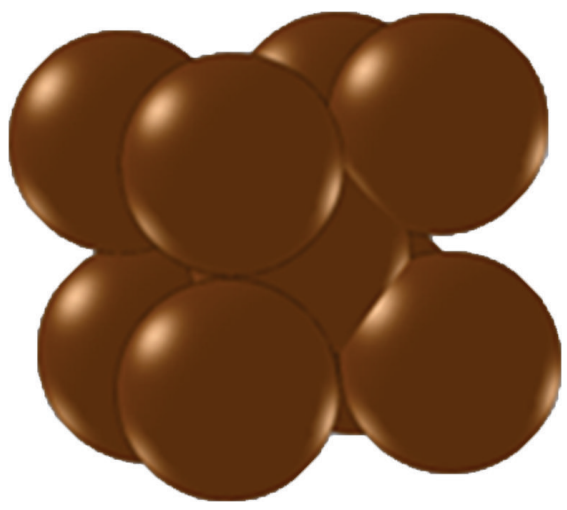

(b)

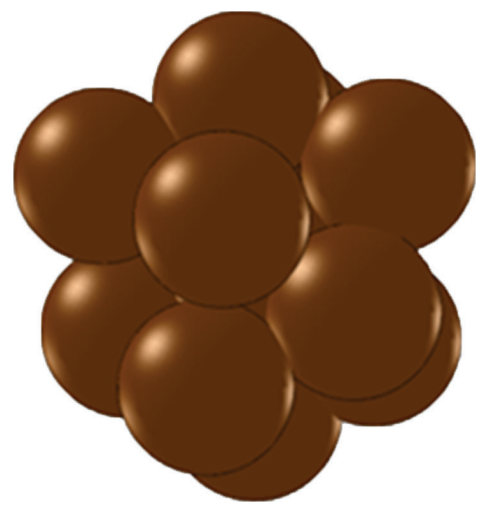

(c)

Figure 6: Arrangements of the silica gel particles for CFD simulation.

have randomly packing of silica gel and not uniform arrangement. So, it was determined that this was the packing arrangement to be used in all CFD simulation.

4.5. CFD Mesh Generation. For all types of geometries the creation of the mesh has different obstacles. In the meshing of silica-gel-packed bed geometry, the major issue is resolving the areas where two solid surfaces touch the contact points.

Because of this fact, the silica gel radii were reduced by about $2 \%$ in order to avoid mesh failures in the area of the silica gel contact points (see Figure 7).

4.6. Porous Media Simulations. A porous material had to be defined for the adsorbent used in the simulation. Materials were found in different sources, one of the source was in ([8] Akisawa, Saha (2001), [3] Akira , Alam (2005)). Type A and Type RD were created with a density of $730 \mathrm{~kg} / \mathrm{m}^{3}$, for type A and a density of $800 \mathrm{~kg} / \mathrm{m}^{3}$, for type RD, a heat capacity of $0.921 \mathrm{~J} / \mathrm{kgK}$, and a thermal conductivity of $0.174 \mathrm{~W} / \mathrm{mK}$ (see Table 2).

By studying the table above, you can see that Type A silica gel and Type RD have similar physical properties which give them similar adsorption/desorption characteristics at different regeneration temperatures [8].
TABLE 2: Thermophysical properties of silica gel.

\begin{tabular}{lccc}
\hline & Type A & Type 3A & Type RD \\
\hline Specific surface area $\left(\mathrm{m}^{2} / \mathrm{g}\right)$ & 650 & 606 & 650 \\
Porous volume $(\mathrm{mL} / \mathrm{g})$ & 0.36 & 0.45 & 0.35 \\
Average pore diameter $(\mathrm{A})$ & 22 & 30 & 21 \\
Apparent density $\left(\mathrm{kg} / \mathrm{m}^{3}\right)$ & 730 & 770 & 800 \\
$\mathrm{pH}$ value & 5.0 & 3.9 & 4.0 \\
Water content $(\mathrm{wt} . \%)$ & $<2.0$ & 0.87 & - \\
Specific heal capacity $(\mathrm{kJ} / \mathrm{kg} \mathrm{K})$ & 0.921 & 0.921 & 0.921 \\
Thermal conductivity $(\mathrm{W} / \mathrm{m} \mathrm{K})$ & 0.174 & 0.174 & 0.198 \\
Mesh sire & $10-40$ & $60-200$ & $10-20$ \\
\hline
\end{tabular}

4.7. Porosity of Silica Gel Used in CFD Simulation. Porosity is the effective porosity of the porous medium, defined as the volume fraction of the interconnected pores with respect to the total porous medium volume; here, the porosity is equal to 0.36 . The porosity will govern the water vapour flow velocity in the porous medium channels, which, in turn, governs porous medium efficiency. The porosity of the granules is defined as the ratio of the volume of the total pore space filled by the fluid to the total volume of the porous medium, all within the domain of interest. Since mesh cells in 


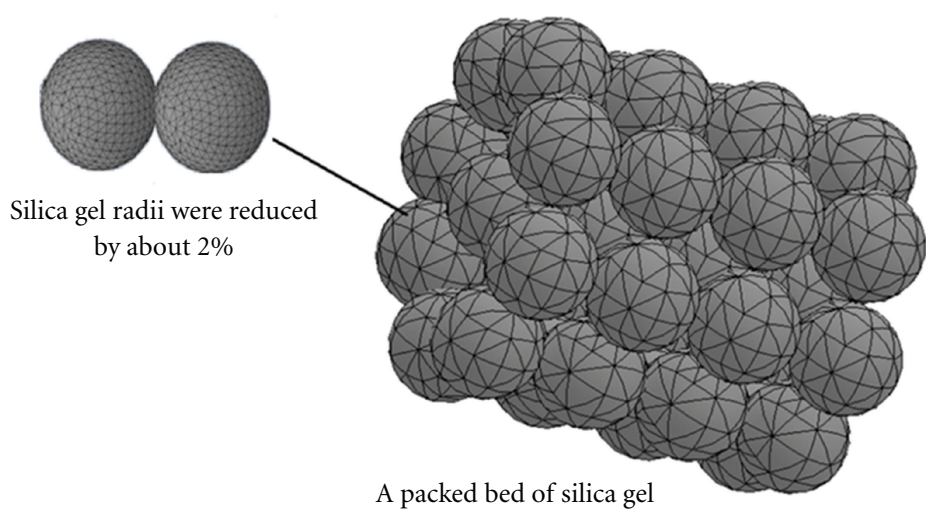

Figure 7: 3D dimensional display and detail of the control volumes in the fluid region near particle-to particle contact points.

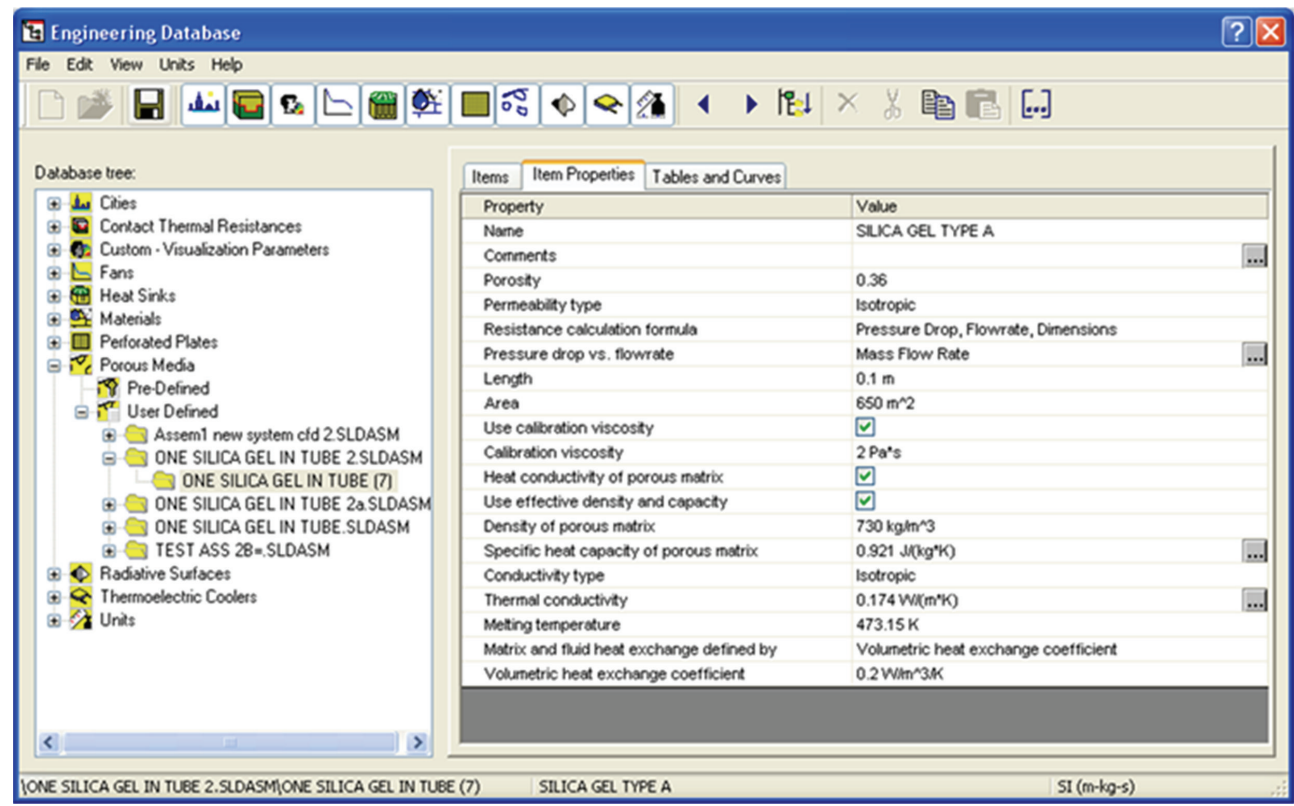

FIGURE 8: To define a porous medium in this simulation you need to specify the porous medium's properties (porosity, permeability type, etc.) in the engineering database and then apply the porous medium to a silica gel in the assembly see Figure 8.

the domain have been tagged as solid or fluid, the volume of total pore space can easily be obtained numerically by finding the sum of volumes of the cells tagged as fluid. Similarly, the volume of the solid matrix is the sum of volumes of the cells tagged as solid. Finally, the total medium volume is simply the sum of the volumes of all cells, see also Figure 9.Then the porosity is defined by the following equation:

$$
\frac{\Delta P}{L}=-\alpha U_{s}^{2}-\beta U_{s}
$$

For some materials which have nonconstant porosity (Benenati and Brosilow), there are various techniques available to generate numerical porous media with the same nonuniform characteristics.

4.8. Pressure Drop and Mass Transfer. The pressure drop and water vapour flow rate caused by the different size of silica
TABLE 3: Simulated pressure drop of different spacer arrangement.

\begin{tabular}{lccc}
\hline $\begin{array}{l}\text { Inlet velocity } \\
(\mathrm{m} / \mathrm{s})\end{array}$ & $\begin{array}{c}\text { Pressure drop } \\
\text { size } 1 \mathrm{~mm} \\
(\mathrm{kPa} / \mathrm{cm})\end{array}$ & $\begin{array}{c}\text { Pressure drop } \\
\text { size } 2 \mathrm{~mm} \\
(\mathrm{kPa} / \mathrm{cm})\end{array}$ & $\begin{array}{c}\text { Pressure drop } \\
\text { size } 3 \mathrm{~mm} \\
(\mathrm{kPa} / \mathrm{cm})\end{array}$ \\
\hline 0.5 & 0.27 & 0.32 & 0.35 \\
1.0 & 0.92 & 1.05 & 1.13 \\
2.0 & 2.19 & 2.60 & 3.02 \\
\hline
\end{tabular}

gel perpendicular to the flow direction together with the mass transfer coefficient are very important in determining optimal packing design.

Table 2 shows the pressure drop for different simulated silica gel size and arrangement.

It can be seen that the pressure drop in the different size of silica gel arrangements in the adsorption tube increased 


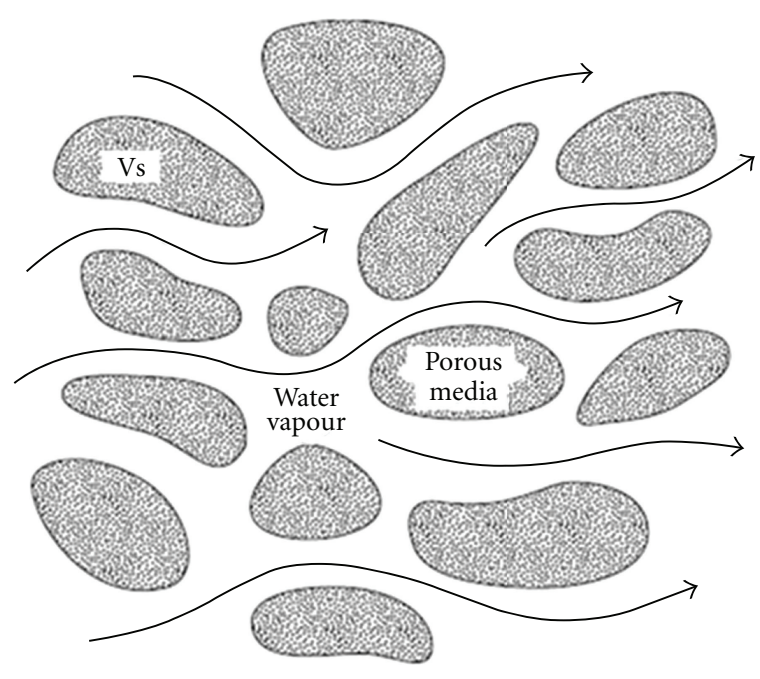

Figure 9: A typical domain of a porous medium two phase problem.

significantly with inlet velocity. The silica gel size $1 \mathrm{~mm}$ has the lowest pressure drop values are observed. This may be partly due to the fact that the diameter of these silica gel arrangement are smaller than the two silica gel $2 \mathrm{~mm}$ and $3 \mathrm{~mm}$ arrangement in the adsorption tubes. The pressure drop for silica gel size $2 \mathrm{~mm}$ is slightly higher than $3 \mathrm{~mm}$ silica gel this is also because of the different size effect on flow of vapour.

4.9. Boundary Conditions Used in Simulation. The boundary conditions determine the flow and thermal variables on the boundaries of the physical model. There are a number of boundary conditions:

(i) flow inlet and exit boundaries: pressure inlet, velocity inlet, pressure outlet;

(ii) wall, repeating, and limit boundaries: wall, symmetry;

(iii) internal fluid, solid;

(iv) internal face boundaries: porous, wall, interior.

In our model we use a velocity inlet at the flow inlet of the adsorption bed, this boundary condition defines a flow velocity at the inlet of the bed. The flow exit boundary is defined as a pressure outlet; the outlet pressure is defined as atmospheric pressure. The bed and packing interiors are defined as boundaries. The wall boundaries separate the fluid zone, vapour, in between the silica gel particles from the wall zones $[4,5,12-14]$.

With the determination of the boundary conditions, the physical model has been defined and a numerical solution can be provided. It was then necessary to determine how the solution will be established. This was done by setting the iteration parameters. With all boundary conditions defined, a number of additional parameters and solving schemes were selected.

An initial condition was assigned to the model and was used to help speed the convergence of the computation. The computation is an iterative process that solves the governing equations for flow and energy in each simulated cell. Depending on the complexity of the model and the computer resources available, CFD simulation can take anywhere from minutes to days [10]. The results of the simulation can be viewed and manipulated with post-processing software once the simulation has converted to a solution.

4.10. Postprocessing the Simulation Data. When the simulation has converged, the last dataset is stored as a final solution. This dataset has a record of the status of all elements in the model, temperature, densities, pressures, flow aspects, and so forth. To be able to interpret the data, it needs to be ordered and reduced to comprehensible sizes [15]. This displaying of the data is called postprocessing and makes it possible to compare the different simulations with each other and with external data. There was as many ways of displaying the data as there were data points so it was important to select the data representation that was required for the desired data comparison. Some of the standard options available are contour plots and velocity vector plots. Contour plots will give a plot in the defined data point collection, this can be a plane or a volume, of contours of another variable. For example, a plane can be defined as a constant $x$ coordinate plane ( $y-z$ plane), we can then make a contour plot showing temperature contours in this plane. In the same plane, a velocity contour plot can be made showing absolute velocities of the fluid in the defined plane. Other variables that can be used for contour plots are magnitude of velocity components, turbulence components, pressure, and so forth. Velocity vector plots can be made to get an insight into the flow patterns in the overall geometry or detailed at specific locations [3, 9-11].

4.11. Fluid Flow Fundamentals. For iteration, CFD solvers use generalized fluid flow and energy balances based on the Navier-Stokes equations. The balances are generalized so the user can influence which elements are added in the balance and which are not. The number of balances to be solved is also user defined; it can be advantageous to not solve all balances initially. The generalized balances that are used by the flow simulation commercial CFD package are the NavierStokes equations for conservation of mass and momentum, when it is set to calculate laminar flow without heat transfer. Additional equations are solved for heat transfer, species mixing or reaction, or $\kappa$ and $\varepsilon$ for turbulent cases [16].

\section{Results and Discussion}

The present CFD simulation attempts to clarify the adsorption characteristics of the adsorption bed packed with spherical silica gel type A under the boundary condition of parameters such as a width of packed bed, the inlet water vapour velocity, and granule size of silica gel.

5.1. Granules Packing Gap between Wall. To be able to solve for turbulent flow in a CFD simulation, it was necessary to introduce a small gap between the wall and the silica gel 


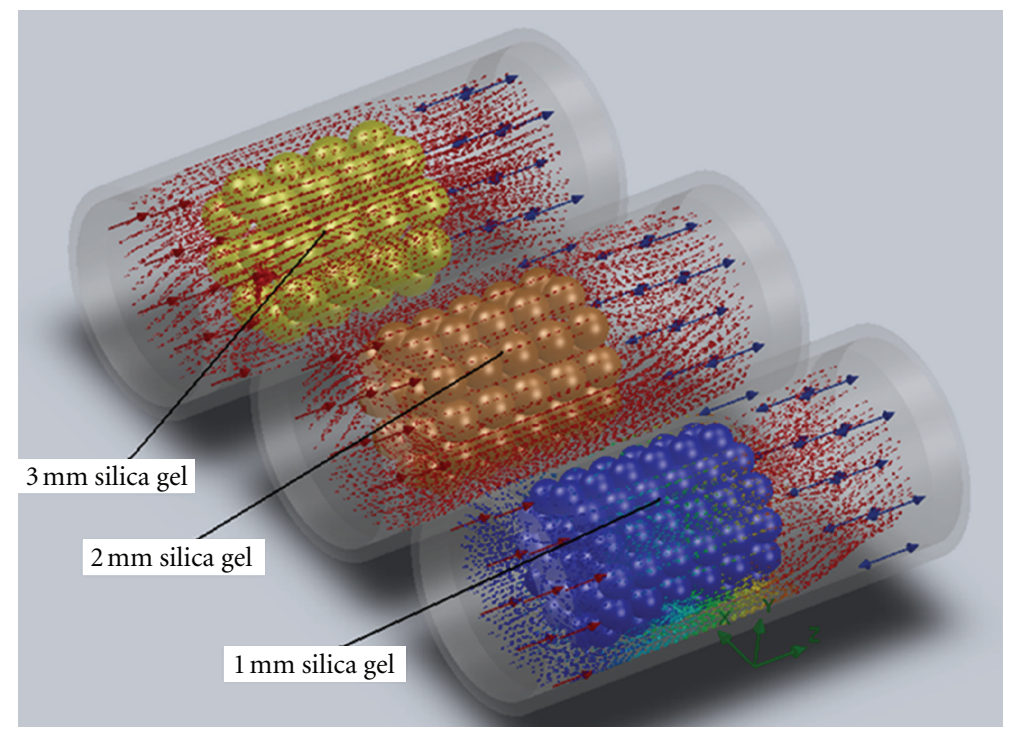

FIGURE 10: Flow profile in an adsorber test beds.
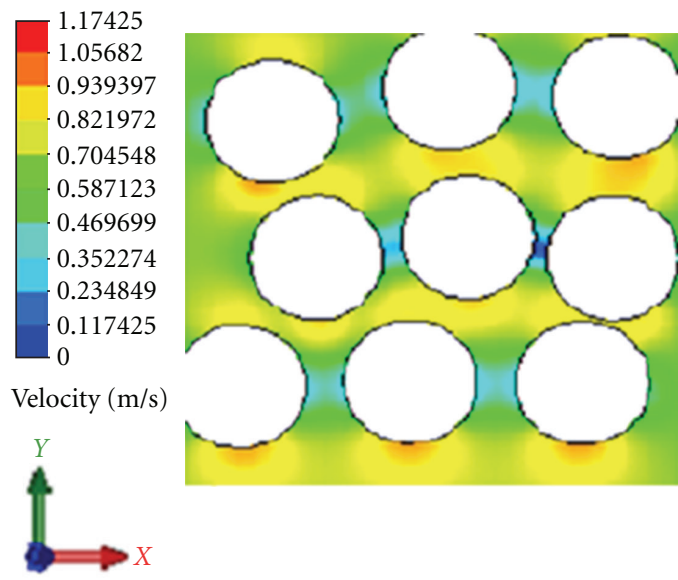

(a)

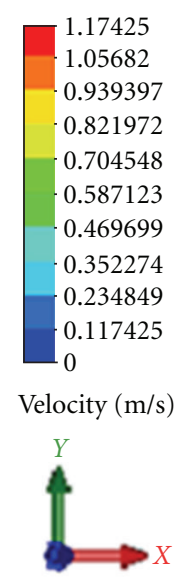

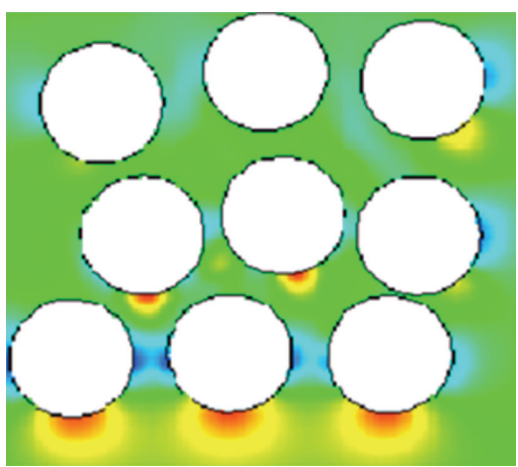

(b)

FIGURE 11: Velocity vectors profile in an axial cut model velocity profile expressed in $\mathrm{m} / \mathrm{s}$.

granules. It was shown from comparisons of flow profiles at several gap sizes that the small gaps used in the final model did not affect the stagnant flow area around the contact points.

\section{CFD Validation against Theoretical Models}

The CFD simulation model has been used to simulate the water vapour adsorption and desorption onto silica gel porous media, heat transfer, and velocity. The results simulated using the CFD model were compared with the experimental data. Based on the simulation results, the data demonstrated a good agreement with the experimental data with maximum error (Figure 10). Based on the good agreement of the model results, several important operating parameters were varied to study the influence of these parameters on water vapour adsorption performance.
6.1. Velocity Profiles. In all CFD simulation, it was notice that the water vapour flow in the middle of the porous media granules and the wall channel as expected. It was also noticed that velocity increased by the inlet and velocity in some constrained areas of the adsorption bed. Stagnation points and secondary flows were also noticed near the contact points (Figure 11).

It can be noticed that all simulations show a good correlation with Ergun's equation, turbulence, and velocity model. The packing of the silica gel granules is clearly visible; also note the practical difference between the interior of the bed and the near-wall region where the packing of the spheres is constrained by the presence of the wall. This lowers the porosity in these regions and a significant fraction of the flow is being channelled through this region.

In (Figure 12) it can be notice that the velocity vectors of water vapour flows in the middle of the silica gel granules 


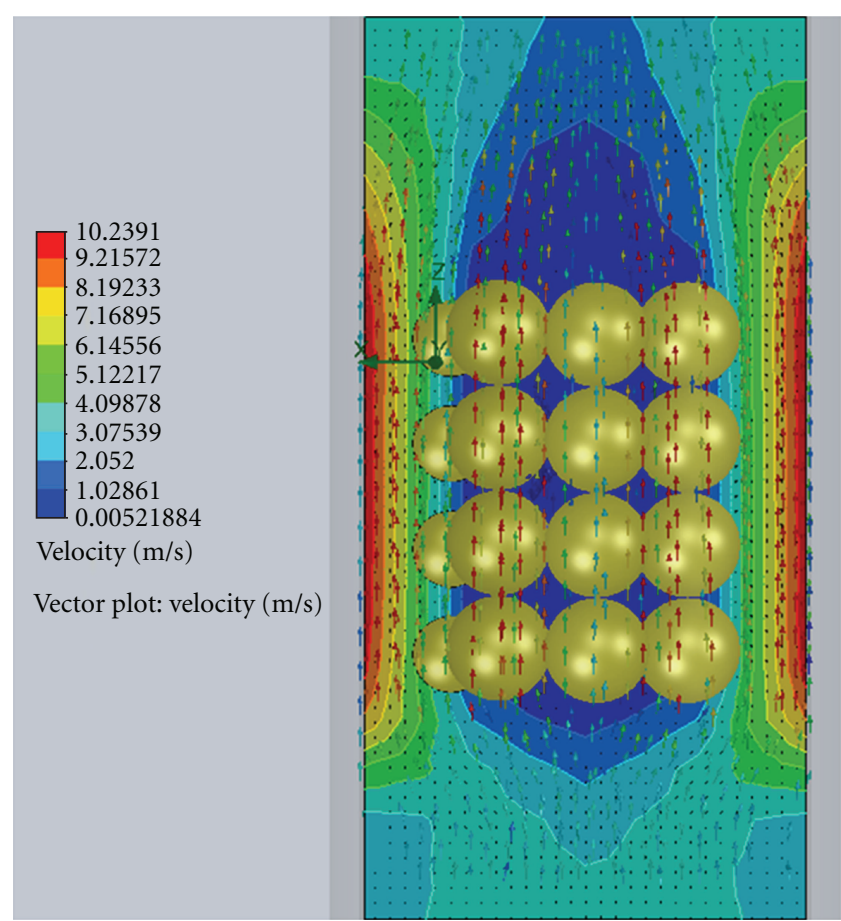

FIGURE 12: Velocity vectors plot of the water vapour velocity field in a packed bed the inlet.

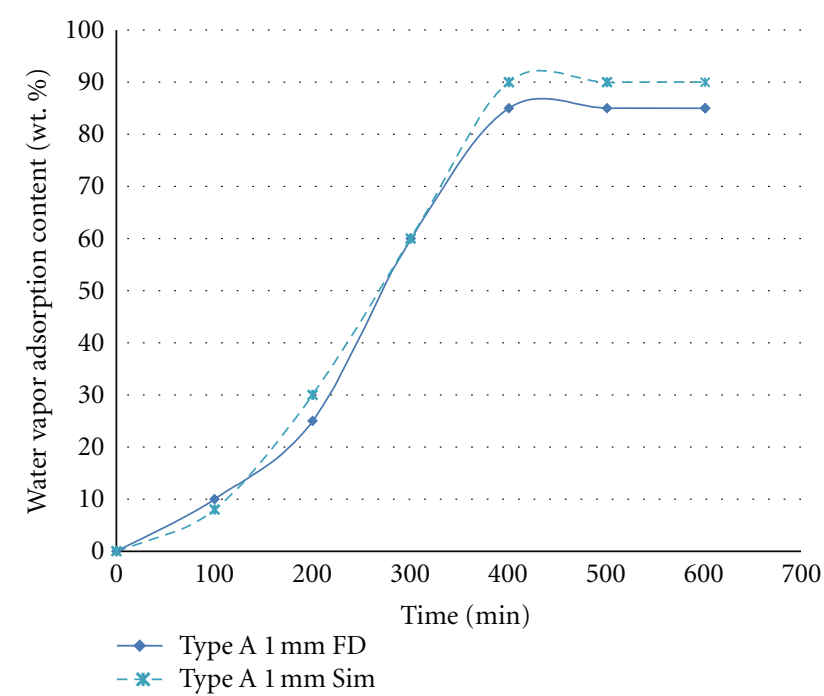

FIgURE 13: Influence of the silica gel size and number on the breakthrough curve.

packing and by the walls of the tube adsorption bed. It can also be seen that the velocity vectors increasing by the inlet of the adsorption bed tube.

One advantage of computational simulation of the flow is the sheer volume of data available for analysis; in particular, here, flow velocities at every point in the bed, which are available for statistical analysis.
6.2. Effect of Flow Velocity. Flow velocity has a directly proportional effect over heat transfer when forced convection takes place. An increase on flow velocity leads to an increase on kinetic energy. This fact generates a better heat transfer coefficient.

The velocity variation within the porous medium depends on the structure of the porous media, as manifested via the pressure drop. The pressure drops occurring across the porous medium are attributed to several factors, including form drag, viscous drag from bounding wall, and inertia force. The obtained results confirm that the pressure drop is a linear function of flow velocity [1-3, 9-17].

6.3. The Performance of the Silica Gel. The performance of the silica gel systems is commonly illustrated and evaluated on the basis of adsorption of the water vapour molecules in the adsorber bed over time. These simulations reveal the impact of silica gel granule adsorption rates:

$$
\bar{C}=\frac{1}{A} \cdot \int_{A} c d A .
$$

Figure 13 shows the resulting CFD simulations with the three example of silica gel. The breakthrough curves become steeper for models that contain smaller silica gel, which is crucial for good adsorption performance of the adsorber bed $[1,5,7,11,15-17]$.

6.4. Water Vapour Flow Profile. The water vapour molecules adsorption accumulation on the silica gel is shown in (Figure 13). In this study, an integrated CFD model was developed to simulate the adsorption dynamics of water vapour of silica gel granules in a fixed bed adsorption column using the Solidworks flow simulation module, the model consists of two modes of operation: the water vapour adsorption and the desorption mode. In each mode, the water vapour flow profile surrounding the granules was determined by solving the Navier-Stokes equations and the resulting velocity profile was regarded time invariant and stored for later use. Also, the time-dependent mass transfer both outside and inside the porous silica gel due to its adsorpitivity was simulated through a user defined function developed to solve the Brunauer, Emmett, and Teller (BET) equation [1] for both adsorption and desorption processes. The developed model was used to determine the adsorption capacity of two different sizes of silica gel granules, namely, $3.5 \mathrm{~mm}$ and $5 \mathrm{~mm}$ as a function of time at different operating temperatures.

In Figure 14, the water molecules stick to the surface of the silica gel the same as the Brunauer, Emmett and Teller model of multilayer adsorption method $[12,13]$, in the CFD simulation, the water vapour molecules is a randomly distributed on to the porous silica gel material surface.

6.5. Water Vapour Adsorption Profile. The CFD simulation determine the distribution of water vapour molecules in the flow vapour phase and the adsorption of adsorbed vapour molecules on the silica gel surfaces. (Figure 15) shows some views of typical adsorption of water vapour molecules (a), 


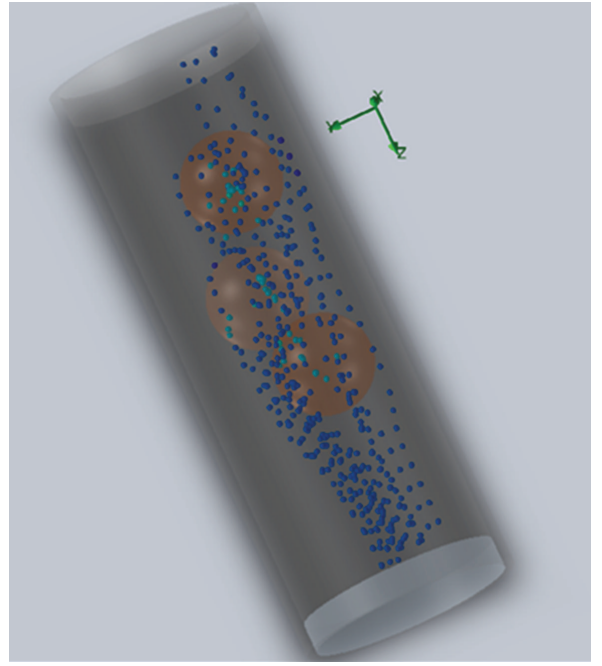

(a)

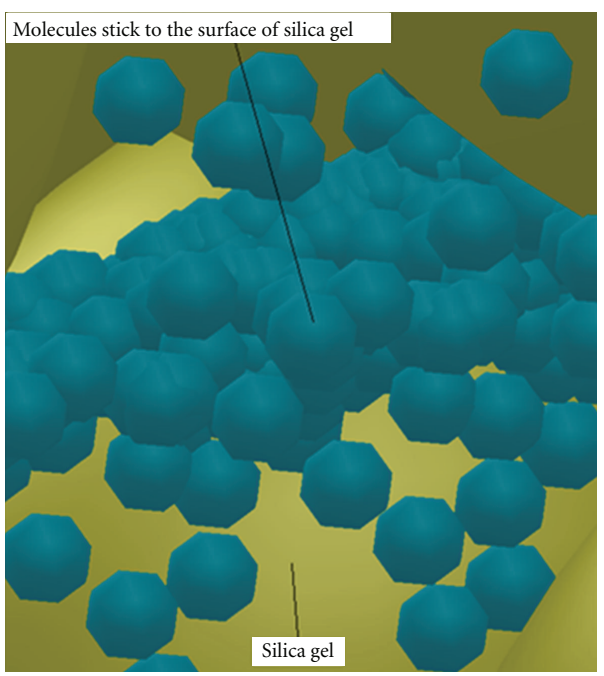

(b)

FIGURE 14: The adsorption starting to take place with the formation of multilayer of adsorbate on adsorbent.

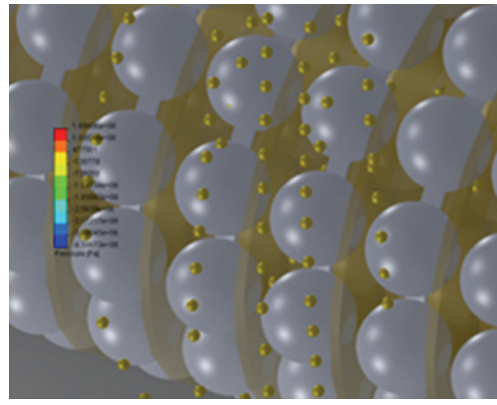

(a) $t=129 \mathrm{sec}$

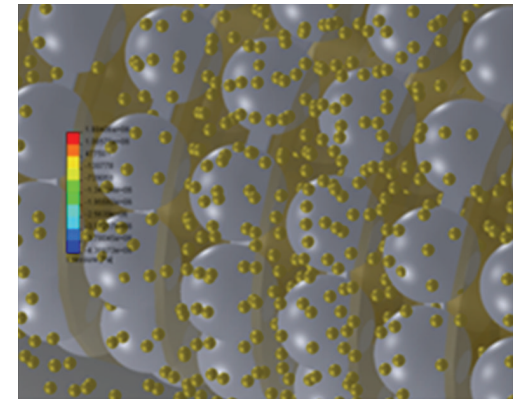

(b) $t=350 \mathrm{sec}$

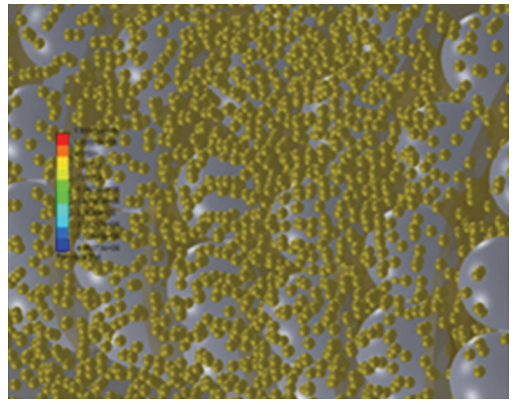

(c) $t=700 \mathrm{sec}$

FIgURE 15: Concentration profiles for $c$ and $q$ at different times in a column filled with 100 silica gel beads.

(b) and (c) at different times of the adsorption of the beds $t=129 \mathrm{sec}, t=350 \mathrm{sec}$, and $t=700 \mathrm{sec}[1,7,8]$.

6.6. CFD Simulation of Desorption of Water Vapour from Silica Gel. When attempting to simulate the desorption of water vapour from silica gel, it was necessary to create a user defined function $(U D F)$; the major challenge in the use of CFD simulation of the desorption of water vapour from silica gel is the complex interconnected void space silica gel has. In traditional 2D mathematical approaches, the engineers use to largely ignoring this fact. In CFD simulation, this is not ignored, it is model into the 3D model of the porous media, see Figure 16. In order to simulate desorption, we had to create a function called desorption that would take several inputs (material, fluid, pressure, flow rate, and whatever factors affect the silica gel calculations).

The desorption of water vapour for silica gel was simulated on a $3 \mathrm{D}$ test with one silica then was tested on a 3 silica gel then ultimately on a 40 silica gel simulation.

6.7. The Heat Transfer Performance. The CFD simulation showed that the heat transfer performance of the silica gel adsorption bed is one of the important factors to affect the adsorption efficiency of the bed. The surface temperature of the silica gel was measured in the simulation to get a batter understand of the heat transfer performance of the silica gel. The water temperatures of $70^{\circ} \mathrm{C}, 80^{\circ} \mathrm{C}$, and $90^{\circ} \mathrm{C}$ were used to heat the silica gel different surface temperatures to help one to understand the heat transfer performance of the adsorber bed with silica gel. Figure 17 shows that the silica gel surface temperature increased steadily in the bigger silica gel sizes as compared to the smaller sizes and its surface temperature was lower than that of the smaller sizes of silica gel. As was expected, the heat transfer performance in the smaller sizes was better than that of the bigger silica gel sizes.

\section{Pros and Cons}

CFD provides a cost-effective means to analyse, demonstrate, and improve the performance of industrial designs; to trouble-shoot manufacturing and process problems. It is a very powerful tool for the simulation of fluid flows. CFD is a knowledge-based activity. It still relies heavily on the knowledge of the user. It is particularly important to 


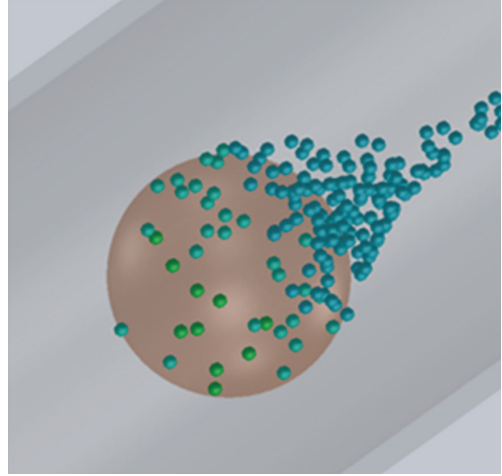

(a)

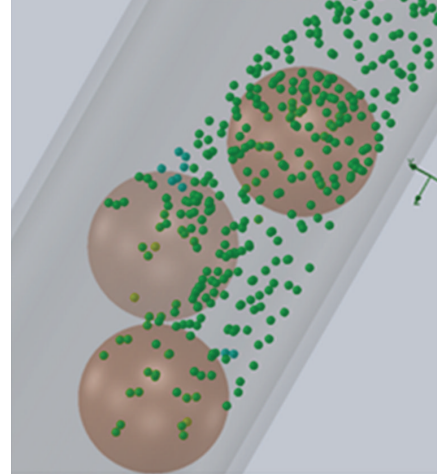

(b)

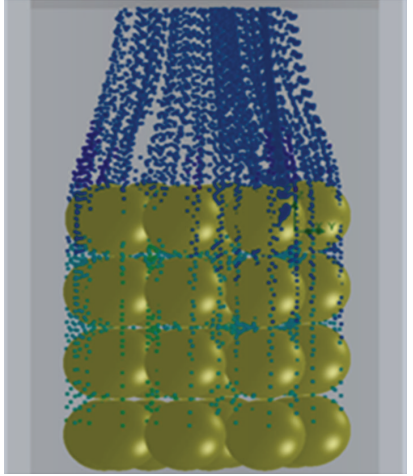

(c)

FIGURE 16: Desorption of water vapour in porous materials.

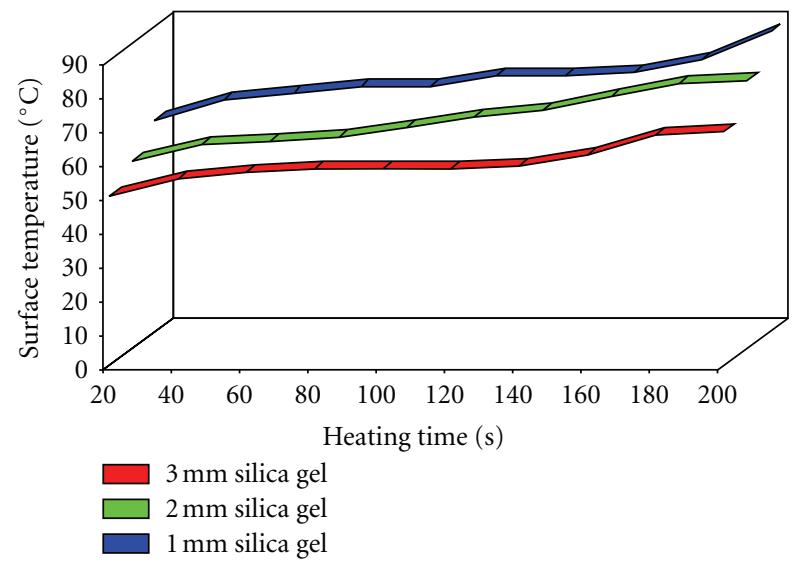

Particles size $=40-60$ mesh

FIGURE 17: The variation of the surface temperature of silica gel size with the heating time.

understand its bounds of applicability and the consequences of limitations in physical and numerical submodels.

\section{Conclusions}

A CFD model was developed for simulating the adsorption of water vapour on silica gel granules and used to study the effect of granule sizes indicating that reducing the granule size increases the adsorption. It can be concluded that CFD is a promising tool in evaluating heat transfer behaviour in an adsorption bed. Further CFD studies, with a larger silica gel and porous medias, are required in the future simulation to show whether they will produce this.

\section{Notations}

a: Surface area of silica gel

$C_{0}$ : Inlet concentration $\left(\mathrm{kg} \mathrm{m}^{-3}\right)$

$C$ : Bed concentration $\left(\mathrm{kg} \mathrm{m}^{-3}\right)$

$\mathrm{C}_{2}$ : Inertia resistance coefficient $(\mathrm{m})$

$D$ : Molecular diffusivity $\left(\mathrm{m}^{2} \mathrm{sec}^{-1}\right)$
$D_{p}:$ Particles diameter $(\mathrm{m})$

$K$ : $\quad$ Mass transfer coefficient $\left(\mathrm{sec}^{-1}\right)$

$P$ : $\quad$ Partial pressure $(\mathrm{Pa})$

$q$ : Adsorbent capacity $\left(\mathrm{mmol} \mathrm{g}^{-1}\right)$

$q_{s}$ : Maximum capacity $\left(\mathrm{mmol} \mathrm{g}^{-1}\right)$

$t: \quad$ Time $(\mathrm{sec})$

$u$ : Water vapour velocity $(x$-direction $)\left(\mathrm{m} \mathrm{sec}^{-1}\right)$

$v$ : Water vapour velocity $(y$-direction $)\left(\mathrm{m} \mathrm{sec}^{-1}\right)$

$w$ : Water vapour velocity ( $z$-direction) $\left(\mathrm{m} \mathrm{sec}^{-1}\right)$.

\section{Greek Symbols}

$\varepsilon:$ Bed fraction (Porosity)

$\rho_{s}$ : Particles density $\left(\mathrm{kg} \mathrm{m}^{-3}\right)$

$\rho$ : Fluid density $\left(\mathrm{kg} \mathrm{m}^{-3}\right)$

$\alpha$ : Viscous resistant coefficient $\left(\mathrm{m}^{-1}\right)$

$\mu$ : Fluid viscosity $\left(\mathrm{Ns} \mathrm{m}^{-2}\right)$

\section{Abbreviation}

CFD: Computational fluid dynamics

LDF: Linear driving force

UDS: User's defined scalars

UDF: User's defined functions.

\section{References}

[1] F. Augier, C. Laroche, and E. Brehon, "Application of computational fluid dynamics to fixed bed adsorption calculations: effect of hydrodynamics at laboratory and industrial scale," Separation and Purification Technology, vol. 63, no. 2, pp. 466474, 2008.

[2] K. S. Chang, M. T. Chen, and T. W. Chung, "Effects of the thickness and particle size of silica gel on the heat and mass transfer performance of a silica gel-coated bed for airconditioning adsorption systems," Applied Thermal Engineering, vol. 25, no. 14-15, pp. 2330-2340, 2005.

[3] A. Akahira and K. C. A. Alam, "Experimental investigation of mass recovery adsorption refrigeration cycle," International Journal of Refrigeration, vol. 28, no. 4, pp. 565-572, 2005.

[4] M. Rahimi and M. Mohseni, "CFD modeling of the effect of absorbent size on absorption performance of a packed bed 
column CFD," Korean Journal of Chemical Engineering, vol. 25, no. 3, pp. 395-401, 2007.

[5] G. E. Mueller, "Radial void fraction distributions in randomly packed fixed beds of uniformly sized spheres in cylindrical containers," Powder Technology, vol. 72, no. 3, pp. 269-275, 1992.

[6] S. Murakami, S. Kato, K. Ito, and Q. Zhu, "Modeling and CFD prediction for diffusion and adsorption within room with various adsorption isotherms," Indoor Air, vol. 13, no. 6, pp. 20-27, 2003.

[7] A. Sakoda and M. Suzuki, "Fundamental study on solar powered adsorption cooling system," Journal of Chemical Engineering of Japan, vol. 17, no. 1, pp. 52-57, 1984.

[8] A. Akisawa, B. B. Saha, K. C. Ng et al., "Experimental investigation of the silica gel-water adsorption isotherm characteristics," Applied Thermal Engineering, vol. 21, no. 16, pp. 1631-1642, 2001.

[9] A. V. Anikeenko, N. N. Medvedev, M. K. Kovalev, and M. S. Melgunov, "Simulation of gas diffusion in porous layers of varying structure," Journal of Structural Chemistry, vol. 50, no. 3, pp. 403-410, 2009.

[10] D. C. Wang, J. Y. Wu, Z. Z. Xia, H. Zhai, R. Z. Wang, and W. D. Doub, "Study of a novel silica gel-water adsorption chiller. Part II. Experimental study," International Journal of Refrigeration, vol. 28, no. 7, pp. 1084-1091, 2005.

[11] J. G. I. Hellström and T. S. Lundström, "Flow through porous media at moderate reynolds number," in Proceedings of the 4th International Scientific Colloquium Modelling for Material Processing, Riga, Latvia, June 2006.

[12] K. S. W. Sing, "Adsorption methods for the characterization of porousmaterials," Advances in Colloid and Interface Science, vol. 76-77, pp. 3-11, 1998.

[13] L. D. Gelb and K. E. Gubbins, "Characterization of porous glasses: simulation models, adsorption isotherms, and the brunauer-emmett-teller analysis method," Langmuir, vol. 14, no. 8, pp. 2097-2111, 1998.

[14] M. F. Liou, A numerical study of transport phenomena in porous media, Ph.D. thesis, Department of Mechanical and Aerospace Engineering, Case Western Reserve University, 2005.

[15] H. Inaba, J. K. Seo, and A. Horibe, "Numerical study on adsorption enhancement of rectangular adsorption bed," Heat and Mass Transfer, vol. 41, no. 2, pp. 133-146, 2004.

[16] C. Horváth and H.-J. Lin, "Band spreading in liquid chromatography: general plate height equation and a method for the evaluation of the individual plate height contributions," Journal of Chromatography A, vol. 149, pp. 43-70, 1978.

[17] J. Goworek and W. Stefaniak, "Investigation on the porosity of silicagel by therm aldesorption of liquids," Materials Chemistry and Physics, vol. 32, no. 3, pp. 244-248, 1992. 

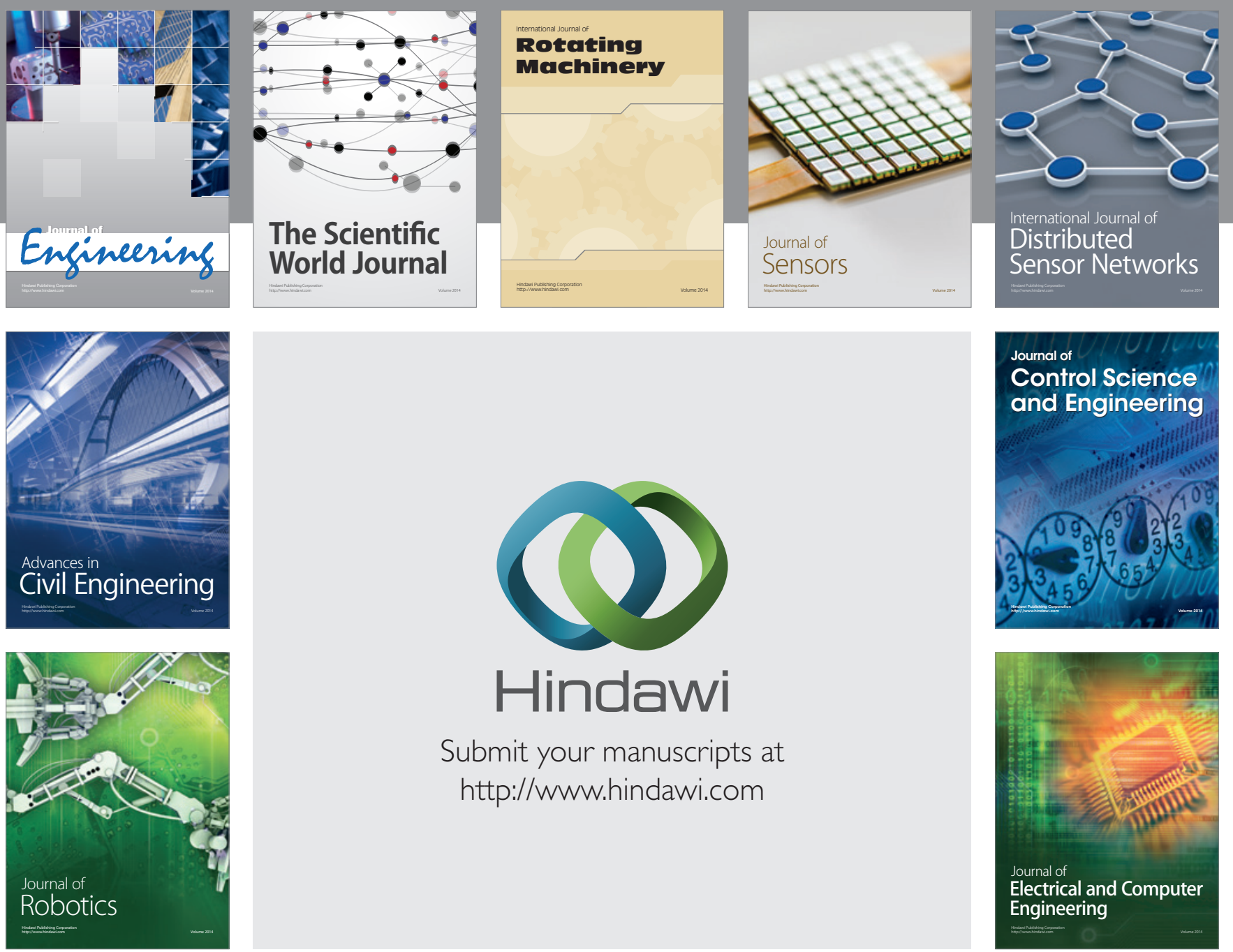

Submit your manuscripts at

http://www.hindawi.com
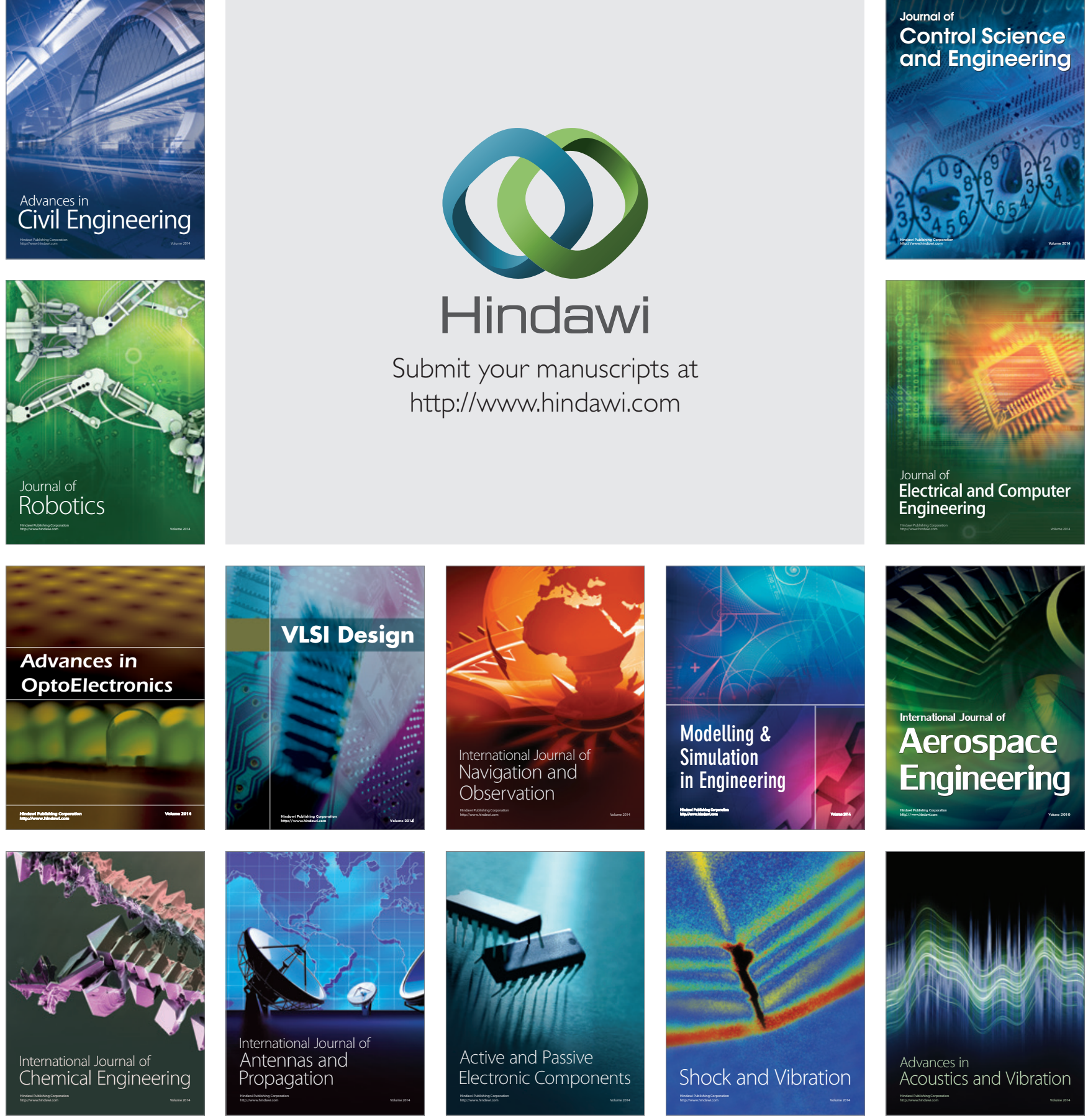